\title{
Understanding Equatorial Atlantic Interannual Variability
}

\author{
Noel S. Keenlyside And MojiB LatiF \\ Leibniz-Institut für Meereswissenschaften, Kiel, Germany
}

(Manuscript received 5 May 2005, in final form 19 May 2006)

\begin{abstract}
An observational-based analysis of coupled variability in the equatorial Atlantic and its seasonality is presented. Regression analysis shows that the three elements of the Bjerknes positive feedback exist in the Atlantic and are spatially similar to those of the Pacific. The cross-correlation functions of the elements of the Bjerknes feedback are also similar and consistent with an ocean-atmosphere coupled mode. However, the growth rate in the Atlantic is up to $50 \%$ weaker, and explained variance is significantly lower. The Bjerknes feedback in the Atlantic is strong in boreal spring and summer, and weak in other seasons, which explains why the largest sea surface temperature anomalies (SSTAs) occur in boreal summer. Its seasonality is determined by seasonal variations in both atmospheric sensitivity to SSTA and SSTA sensitivity to subsurface temperature anomalies.
\end{abstract}

\section{Introduction}

Studies of tropical Atlantic variability over the past two decades have shown that on interannual time scales coherent SST variability occurs in three main regions: the north tropical Atlantic (NTA), equatorial Atlantic, and southern subtropical Atlantic (e.g., Enfield and Mayer 1997; Huang et al. 2004). Two different types of coupled variability have been proposed: a dipole or meridional mode (e.g., Chang et al. 1997) and an equatorial mode (Zebiak 1993), which is similar to El NiñoSouthern Oscillation (ENSO) in the Pacific. The region is also thought to be influenced by remote forcing from the tropical Pacific and the extratropics (e.g., Enfield and Mayer 1997).

The NTA region and dipolelike mode have received the most attention. There is now some consensus on the causes (Enfield and Mayer 1997; Chang et al. 2000; Saravanan and Chang 2000; Sutton et al. 2000) and predictability (Penland and Matrosova 1998; Chang et al. 2003) of variability in the NTA region. It is also generally agreed that no coupled dipole exists on interannual time scales (e.g., Enfield and Mayer 1997), and this is probably also true on decadal time scales (Dommenget and Latif 2000). However, the sensitivity of the atmo-

Corresponding author address: Noel S. Keenlyside, LeibnizInstitut für Meereswissenschaften, Düsternbrooker Weg 20, D-24105 Kiel, Germany.

E-mail: nkeenlyside@ifm-geomar.de sphere to cross-equatorial SST gradients is recognized (Chiang et al. 2002), but it is not clear if it results in a positive ocean-atmosphere feedback (Chang et al. 2000; Sutton et al. 2000).

The Atlantic equatorial mode of variability, also referred to as the equatorial zonal mode or Atlantic Niño mode, is the focus of this paper. Although its similarities to ENSO have been recognized since the 1980s (Merle et al. 1980; Servain et al. 1982; Hirst and Hastenrath 1983; Philander 1986), significant differences do exist, and a good understanding of the variability still evades us. The main differences to ENSO are the significantly weaker variability, the much shorter duration (3 months) of extreme warm/cold events, and spectral characteristics hardly discernable from red noise (Zebiak 1993; Carton and Huang 1994; Latif and Grötzner 2000). Predictability also appears significantly lower. Nonetheless, this type of variability is associated with significant impacts over land (Hirst and Hastenrath 1983; Wagner and da Silva 1994; Carton and Huang 1994), which are potentially predictable (Goddard and Mason 2002), and is thus of practical importance. Given that the potential predictability of the atmosphere is greatest in the deep Tropics (e.g., Sutton et al. 2000), and any dynamical similarities to ENSO may open the possibilities for useful longer-term predictability, this region deserves more attention.

One way to assess the similarities of equatorial Atlantic and Pacific variability is to investigate any similarities in the coupled ocean-atmosphere feedbacks.

DOI: $10.1175 /$ JCLI3992.1 
The basin sizes and the distribution of land masses are very different for the Atlantic and Pacific, and there is no permanent equatorial warm pool or equatorial convection in the Atlantic. Despite this the climates of the two basins are very similar: easterly surface winds, an equatorial cold tongue, an upward sloping thermocline toward the east, and similar annual cycles of winds and SST. These similarities imply the existence of similar coupled ocean-atmosphere feedbacks.

ENSO is the result of a positive ocean-atmosphere feedback, which is commonly referred to as the Bjerknes feedback, and a delayed negative ocean feedback. The Bjerknes feedback consist of three elements: forcing of surface winds in the west by SST anomalies (SSTAs) in the east, forcing of heat content (HC) anomalies in the east by the winds to the west, and the forcing of SSTA in the east by HC anomalies there. As now summarized, individual elements of the Bjerknes feedback in the Atlantic have already been investigated separately. Despite its equal importance, the delayed negative ocean feedback has not received much attention and is also not the focus of this work.

Analysis of observations in the Atlantic indicates that there is a link between SST and surface winds to the west (Servain et al. 1982; Hirst and Hastenrath 1983), and that the structure of the response in the wind field is similar to that in the Pacific (Zebiak 1993). Results from atmosphere general circulation models (AGCMs) forced by observed SST also show that the atmosphere is indeed sensitive to eastern Atlantic SSTA, although the sensitivity varies seasonally and is model dependent (Chang et al. 2000; Sutton et al. 2000).

Western Atlantic (WAtl) zonal winds clearly force $\mathrm{HC}$ variations in the east, but whether this forcing dominates the variability there is not clear. Analysis of expendable bathyothermograph (XBT)-derived HC data indicates only a weak relationship (Vauclair and du Penhoat 2001). However, this is most likely due to poor data quality, as observations show that western Atlantic wind variations precede eastern Atlantic SSTA by a month (Servain et al. 1982), and OGCM simulations show that western Atlantic zonal wind fluctuations, primarily through long equatorial waves (Illig et al. 2004), are a major forcing of eastern Atlantic HC variations (Carton and Huang 1994; Servain et al. 2000).

For subsurface temperature anomalies to affect SST, the vertical advection of subsurface temperature anomalies must be an important term in the SST budget. Analysis of observed $\mathrm{HC}$ data suggests that only a weak relationship exists in the east (correlation $\approx 0.2$, Vauclair and du Penhoat 2001). Ocean modeling results again indicate a much stronger relation (correlation $>$ 0.6) (Carton and Huang 1994; Servain et al. 2000).

Models provide an alternative method to assess whether coupled ocean-atmosphere feedbacks exist in the Atlantic and are strong enough to support coupled variability. The Zebiak (1993) intermediate complexity model (ICM) of the Atlantic simulates a coupled mode with a period of $4 \mathrm{yr}$. The mode has similar physics to ENSO, but owing to the different background state, it is strongly damped and only sustained by external forcing. This is consistent with results from hybrid coupled models (HCMs) (Latif and Barnett 1995; Nobre et al. 2003). The simulation of realistic equatorial coupled variability by coupled general circulation models (CGCMs) is problematic, since the models have major difficulties in simulating the climate of the region (Davey et al. 2002). However, coupled models that simulate ENSO-like variability in the Atlantic do exist with (Latif and Grötzner 2000) and without (Wu et al. 2002; Huang et al. 2004) flux adjustment.

EOF analysis of observations indicates that coherent variability among surface winds, HC, and SST, similar to that in the Pacific exists in the equatorial Atlantic (Ruiz-Barradas et al. 2000). However, spectral analysis shows that the variability is only weakly oscillatory (2yr period) and otherwise similar to a red noise process (Latif and Grötzner 2000; Ruiz-Barradas et al. 2000). Thus, while theoretical considerations and modeling results suggest that equatorial Atlantic variability has similarities to ENSO, observational evidence remains weak.

Another poorly understood feature of the equatorial Atlantic mode is its strong tendency to peak in boreal summer, in contrast to ENSO, which peaks in boreal winter. No complete explanation has been given yet for this characteristic. Latif and Grötzner (2000) propose that it arises from the annual cycle of thermocline depth, through modulating the strength of subsurfacesurface coupling, and that only in boreal summer is the thermocline close enough to the surface to allow subsurface temperature anomalies to affect SST. This link was first pointed out by Merle et al. (1980) and is consistent with observational (Houghton and Colin 1986) and modeling (Carton and Huang 1994) studies.

In the same way, seasonal modulations of oceanatmosphere coupling also likely contribute to the seasonality of the variability. AGCM experiments have shown that the atmosphere is sensitive to eastern Atlantic SSTA in boreal fall (Chang et al. 2000; Sutton et al. 2000). There is less agreement in other seasons: Chang et al. (2000) find no sensitivity in other seasons; while Sutton et al. (2000) suggest that the Bjerknes coupling is present in boreal summer, and probably also 
in boreal spring. However, in boreal spring the atmosphere is most sensitive to cross-equatorial SST gradients (Chang et al. 2000; Sutton et al. 2000; Chiang et al. 2002), and it is hard to separate the two responses. In addition, both may be linked (Servain et al. 1999, 2000).

The aim of this work is to address the two questions raised above: first, to what degree are positive oceanatmosphere feedbacks, similar to those in the Pacific, present in the equatorial Atlantic? Second, what determines the phase locking of the variability to the annual cycle? To address the first question, we investigate the individual components of the Bjerknes feedback, and assess their strength (section 3a). We conclude that a weak Bjerknes feedback exists in the Atlantic. Having found a Bjerknes feedback to exist, we address the second question by analyzing the seasonality of its three elements and conclude that it is able to explain the seasonality of the variability (section $3 b$ ). This study differs from previous ones, in that the full Bjerknes feedback and its seasonality are estimated. Other studies have only investigated individual components.

The paper is structured as follows. Section 2 summarizes the observational data and analysis methods used in this study. This includes a description of how statistical significance is estimated. In section 3a, the strength of the Bjerknes feedback is estimated using linear regression analysis. In section $3 \mathrm{~b}$, the seasonality of coupling, among atmosphere, SST, and ocean HC in the equatorial Atlantic (i.e., the three elements of the Bjerknes feedback), is similarly estimated. In both sections, results are contrasted with those of the Pacific. Discussion and conclusions are presented in the final section.

\section{Data and methods}

The data, which are primarily observational, and the analysis methods used throughout this paper are now briefly described. Surface atmospheric data are taken from two sources. Sea level pressure and surface (10-m) wind speed, and the zonal and meridional components of the wind speed are taken from the gridded Comprehensive Ocean Atmosphere Data Set [COADS; da Silva et al. (1994)], which is a compilation of primarily volunteer observing ship measurements. Only the standard COADS products are used here, and only for the period 1950 to 1997. Much of the analysis carried out on the COADS wind data are also repeated with surface stress data from the National Centers for Environmental Prediction-National Center for Atmospheric Research (NCEP-NCAR) reanalysis (Kalnay et al. 1996) for the period 1950 to 2002, to give some indication of the sensitivity of our results to different datasets.

SST data are taken from the Hadley Centre Sea Ice and Sea Surface Temperature dataset version 1.1
(HadISST 1.1), which is an EOF-based reconstruction of observations extending back from the present until 1870 (Rayner et al. 2003), and are provided by the British Atmospheric Data Center (http://badc.nerc.ac.uk/ home/). Gridded HC (averaged over the upper $400 \mathrm{~m}$ ), compiled from XBT measurements, are used for the period 1970 to 2003 . The data extend back to 1955 , but their quality becomes noticeably poorer before 1970 . The data quality and the analysis and gridding method are discussed in Tourre and White (1995). The data were provided by the Joint Environmental Data Analysis Center (JEDA; http://jedac.ucsd.edu/index.html). Sea level observations processed from Ocean Topography Experiment (TOPEX)/Poseidon, JASON, and ERS satellite data are also used for the period January 1993 until December 2002. These data were compiled within the Enhanced Ocean Data Assimilation and Climate Prediction European Union Project (http:// www.cls.fr/html/oceano/projets/enact/). In the Tropics, where the ocean can be approximated by a 1.5-layer system, sea level variations are closely related to thermocline perturbations, and thus these data are a good proxy for both thermocline depth and upper-ocean HC variations. Furthermore the data are of much higher quality than those derived from XBT measurements. These observational ocean data are complemented with data from an NCEP-forced simulation of the Max Planck Institute for Meteorology Ocean Model (MPIOM) (Marsland et al. 2003) for the period 1950 to 2001, using standard bulk formulas for the calculation of heat fluxes and a weak relaxation of surface salinity to the Levitus et al. (1994) climatology.

The bulk of the results in this paper are obtained by standard linear correlation and regression analysis. In all calculations, time series are linearly detrended and anomalies are calculated with respect to the period considered. Where appropriate the significance of the results is estimated using the standard two-sided Student's $t$ test, assuming a null hypothesis of no correlation. To account for serial correlation, the number of degrees of freedom is reduced by a factor equal to the inverse of the decorrelation time ${ }^{1}$ (Davis 1976). In the case of one index and a field, the decorrelation time of the index is used, and in the case of two indices, the longest decorrelation time is taken. Yearly mean data are assumed to be independent of each other. Various more complex methods exist for estimating the significance of correlations among serial correlated data (e.g., Ebisuzaki 1997). Here a simple method is adopted,

\footnotetext{
${ }^{1}$ The decorrelation time is defined here as the first zerocrossing or first minimum if it occurs before the autocorrelation function.
} 
since in our opinion issues of data quality are of more concern.

\section{Coupled variability in the equatorial Atlantic and its relation to the annual cycle}

Are positive ocean-atmosphere feedbacks, similar to those known to be crucial to ENSO variability in the Pacific Ocean, active in the equatorial Atlantic, that is, is the Bjerknes feedback active? In this section we address this question by analyzing the three elements of the Bjerknes feedback in the observations: the coupling between 1) SST and zonal wind stress, 2) zonal wind stress and ocean dynamics, and 3) ocean dynamics and SST. Following this, the coupled interactions are estimated for each calendar month, to help explain the tight phase locking of the variability to the annual cycle.

\section{a. The mean Bjerknes feedback}

The first element of the Bjerknes feedback loop is the strong relationship between eastern Pacific SSTA and central Pacific surface zonal winds. In the Atlantic it has been also long recognized that eastern Atlantic SSTA and western Atlantic winds are related (Servain et al. 1982; Hirst and Hastenrath 1983; Zebiak 1993). The regression of monthly anomalies of Atlantic3 $\left(3^{\circ} \mathrm{S}-\right.$ $3^{\circ} \mathrm{N}, 20^{\circ} \mathrm{W}-0^{\circ}$ ) SSTA onto surface zonal winds shows the typical ENSO-like pattern, with westerly winds to the west of the positive SSTA and easterly anomalies to the east (Fig. 1a). Regression values indicate that a $1{ }^{\circ} \mathrm{C}$ change in SST corresponds to maximum westerly wind anomaly of between $0.6-0.8 \mathrm{~m} \mathrm{~s}^{-1}$ (Fig. 1a), or 0.55 $\mathrm{m} \mathrm{s}^{-1}$ when averaged over the western Atlantic $\left(3^{\circ} \mathrm{S}-\right.$ $3^{\circ} \mathrm{N}, 40^{\circ}-20^{\circ} \mathrm{W}$ ) region (Table 1$)$. In the Pacific, an equivalent SST change would result in maximum westerly anomalies between 1.2 and $1.4 \mathrm{~m} \mathrm{~s}^{-1}$ (not shown) or $0.84 \mathrm{~m} \mathrm{~s}^{-1}$ for the Niño-4 region (Table 1). In the Atlantic, this relationship explains a little more than $10 \%$ of the variability, whereas in the Pacific explained variances approach $20 \%$. These results suggest that the coupling between eastern basin SST and westerncentral basin surface wind anomalies is weaker and less dominant in the Atlantic than in the Pacific. An analysis of NCEP surface stress data produces essentially the same result, except explained variances are higher in both basins (Table 1). As discussed further below, these differences between the Pacific and the Atlantic are likely due to the lack of a permanent western basin warm pool in the Atlantic.

The second element of the Bjerknes feedback is the link between western Pacific surface winds and variations in eastern Pacific thermocline depth. The regression of western Atlantic zonal surface stress onto sea level anomalies (SLAs) indicates that westerly wind (a)

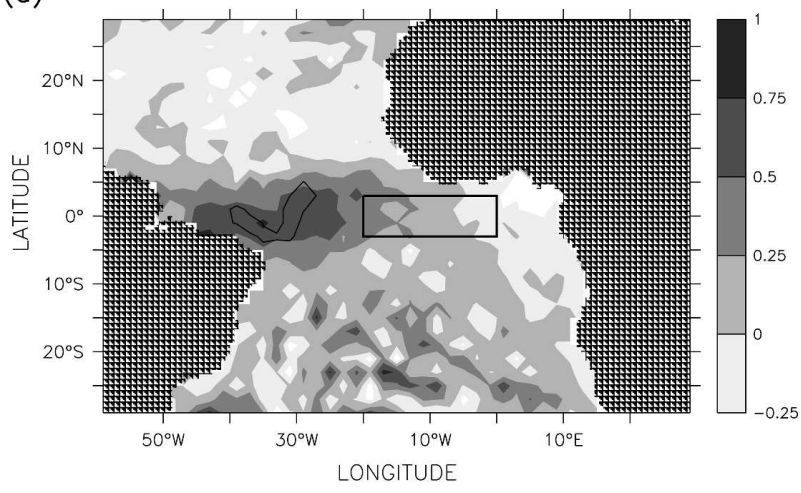

(b)

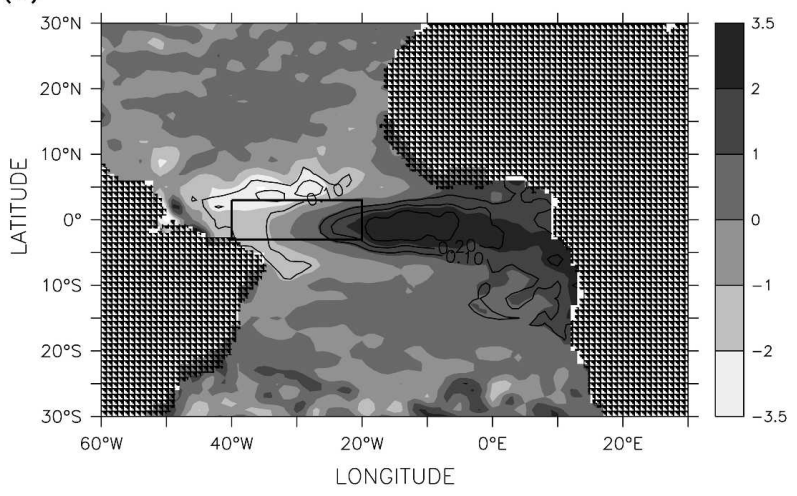

(c)

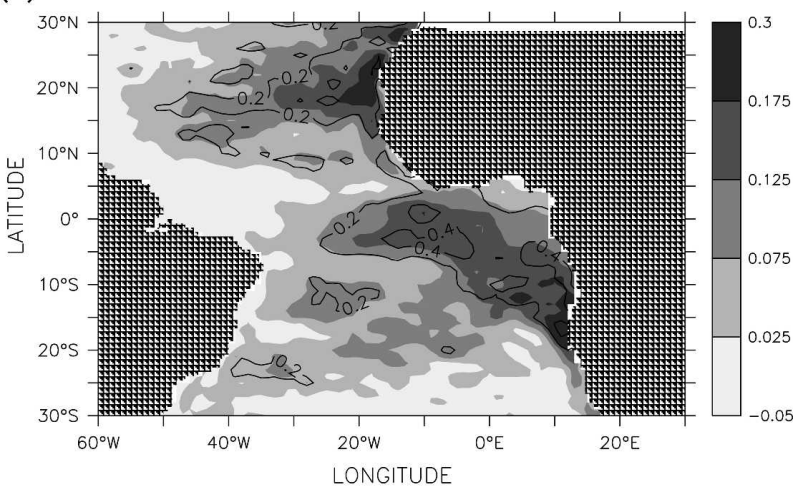

FIG. 1. (a) Regression between Atlantic3 (black box) averaged SSTAs and 10-m zonal wind speed. (b) Regression between WAtl (black box, $3^{\circ} \mathrm{S}-3^{\circ} \mathrm{N}, 40^{\circ}-20^{\circ} \mathrm{W}$ ) zonal wind stress anomalies and SLAs. (c) Regression between SLAs and SSTAs. Explained variance is overlaid with a contour interval of 0.1 , except in (c) where the interval is 0.2. SST data are from HadISST, sea level data are from satellite measurements, 10-m winds are from COADS, and surface stress are from the NCEP-NCAR reanalysis. The period considered in (a) and (c) is 1993-2002, and in (b) it is 1950-97. Explained variances greater than $0.08,0.28$, and 0.36 are significant at the $95 \%$ level in (a), (b), and (c), respectively.

anomalies correspond to an increase in SLA and HC in the eastern equatorial Atlantic and a decrease in SLA and $\mathrm{HC}$ in the western Atlantic particularly off the equator (Fig. 1b). This pattern closely resembles that of 
TABLE 1. Statistical analysis of the Bjerknes feedback in the Atlantic and Pacific. Listed are the dependent $(X)$ and independent $(Y)$ variables, data period, correlation $(r)$ and regression $(a)$ values, regression value units, lag in months of maximum correlation $(1)$, maximum correlation $\left(r_{l}\right)$ and regression $\left(a_{l}\right)$ values, and the $95 \%$ significance level for correlation. The indices used are the Atlantic3 $\left(\right.$ Atl $3 ; 3^{\circ} \mathrm{S}-3^{\circ} \mathrm{N}, 20^{\circ} \mathrm{W}-0^{\circ}$ ), western equatorial Atlantic (WAtl; $3^{\circ} \mathrm{S}-3^{\circ} \mathrm{N}, 40^{\circ}-20^{\circ} \mathrm{W}$ ), Niño-3, and Niño-4. SST data are from HadISST, 10-m zonal winds (U10) are from COADS, zonal surface stress (Ustr) are from the NCEP-NCAR reanalysis, sea level anomalies (SLAs) are derived from satellite measurements, 400-m HSTs are from JEDA, and 400-m average temperature anomalies (Tave) are from a forced OGCM simulations. All data and statistical techniques are described in section 2.

\begin{tabular}{|c|c|c|c|c|c|c|c|c|c|}
\hline$X$ & $Y$ & Period & $r_{0}$ & $a_{0}$ & {$[a]$} & $l$ & $r_{l}$ & $a_{l}$ & $r_{95}$ \\
\hline \multicolumn{10}{|c|}{ SST-Surface zonal wind } \\
\hline \multicolumn{10}{|c|}{ Atlantic } \\
\hline Atl3-SST & WAtl-U10 & 1950-1997 & 0.48 & 0.55 & $\mathrm{~m} \mathrm{~s}^{-1 \circ} \mathrm{C}^{-1}$ & -1 & 0.52 & 0.60 & 0.28 \\
\hline Atl3-SST & WAtl-Ustr & 1950-2002 & 0.52 & 0.75 & $10^{-2} \mathrm{~Pa}{ }^{\circ} \mathrm{C}^{-1}$ & 0 & 0.52 & 0.75 & 0.27 \\
\hline \multicolumn{10}{|c|}{ Pacific } \\
\hline Niño-3-SST & Niño-4-U10 & 1950-1997 & 0.66 & 0.84 & $\mathrm{M} \mathrm{s}^{-1 \circ} \mathrm{C}^{-1}$ & -2 & 0.67 & 0.86 & 0.28 \\
\hline Niño-3-SST & Niño-4-Ustr & 1950-2002 & 0.68 & 0.74 & $10^{-2} \mathrm{~Pa}{ }^{\circ} \mathrm{C}^{-1}$ & -1 & 0.70 & 0.76 & 0.28 \\
\hline \multicolumn{10}{|c|}{ Surface zonal wind-HC } \\
\hline \multicolumn{10}{|c|}{ Atlantic } \\
\hline WAtl-Ustr & Atl3-SLA & 1993-2002 & 0.59 & 2.2 & $\mathrm{~cm}\left(10^{-2} \mathrm{~Pa}\right)^{-1}$ & 0 & 0.59 & 2.2 & 0.53 \\
\hline WAtl-U10 & Atl3-HST & 1970-1997 & 0.22 & 1.4 & $10^{8} \mathrm{~J} \mathrm{~m}^{-1} \mathrm{~s}^{-1}$ & 1 & 0.22 & 1.4 & 0.28 \\
\hline Watl-Ustr & Atl3-Tave & 1950-2001 & 0.58 & 0.27 & ${ }^{\circ} \mathrm{C}\left(10^{-2} \mathrm{~Pa}\right)^{-1}$ & 1 & 0.62 & 0.29 & 0.31 \\
\hline \multicolumn{10}{|c|}{ Pacific } \\
\hline Niño-4-Ustr & Niño-3-SLA & 1993-2002 & 0.82 & 6.0 & $\mathrm{~cm}\left(10^{-2} \mathrm{~Pa}\right)^{-1}$ & 1 & 0.87 & 6.3 & 0.63 \\
\hline Niño-4-U10 & Niño-3-HST & 1970-1997 & 0.71 & 3.8 & $10^{8} \mathrm{~J} \mathrm{~m}^{-1} \mathrm{~s}^{-1}$ & 1 & 0.74 & 4.0 & 0.32 \\
\hline Niño-4-Ustr & Niño-3-Tave & 1950-2001 & 0.73 & 0.44 & ${ }^{\circ} \mathrm{C}\left(10^{-2} \mathrm{~Pa}\right)^{-1}$ & 1 & 0.80 & 0.49 & 0.31 \\
\hline \multicolumn{10}{|c|}{ HC-SST } \\
\hline \multicolumn{10}{|c|}{ Atlantic } \\
\hline Atl3-SST & Atl3-SLA & 1993-2002 & 0.69 & 0.17 & ${ }^{\circ} \mathrm{C} \mathrm{cm}^{-1}$ & 1 & 0.73 & 0.18 & 0.6 \\
\hline Atl3-SST & Atl3- HST & 1970-2002 & 0.43 & 0.06 & ${ }^{\circ} \mathrm{C}\left(10^{8} \mathrm{~J}\right)^{-1}$ & 1 & 0.46 & 0.06 & 0.34 \\
\hline \multicolumn{10}{|c|}{ Pacific } \\
\hline Niño-3-SST & Niño-3-SLA & 1993-2002 & 0.90 & 0.12 & ${ }^{\circ} \mathrm{C} \mathrm{cm}^{-1}$ & 1 & 0.94 & 0.12 & 0.6 \\
\hline Niño-3-SST & Niño-3- HST & 1970-2002 & 0.81 & 0.12 & ${ }^{\circ} \mathrm{C}\left(10^{8} \mathrm{~J}\right)^{-1}$ & 1 & 0.83 & 0.12 & 0.34 \\
\hline
\end{tabular}

the Pacific (i.e., from the regression of Niño-4 winds onto SLA; not shown), but regression values are smaller and explained variance lower. In the Pacific, a $10^{-2} \mathrm{~Pa}$ westerly surface zonal stress anomaly over the Niño-4 region corresponds to a $6-\mathrm{cm}$ rise in sea level to the east (Table 1). In the Atlantic, a $10^{-2} \mathrm{~Pa}$ westerly surface zonal stress anomaly over the WAtl region corresponds to a $2-\mathrm{cm}$ rise in sea level to the east (Fig. lb; Table 1). In the Pacific, this relation accounts for up to $70 \%$ of the variability, whereas in the Atlantic it only accounts for $30 \%$. These values are consistent with those calculated over the period 1950-2001 using data from the forced ocean simulation (Table 1). For XBTderived data the relationship is much weaker (Table 1), which is consistent with the Vauclair and du Penhoat (2001) analysis of subsurface data for the period 1979 to 2000. As described later, this is likely due to data quality issues. Thus, observations indicate that the second element of the Bjerknes feedback loop is also active in the Atlantic, but weaker and less dominant than in the Pacific.
The last element of the Bjerknes feedback is the coupling between ocean dynamics and SST variability. In the case of ENSO it is well understood that the dominant term coupling ocean dynamics and SST in the eastern equatorial Pacific is the mean vertical advection of anomalous temperature (e.g., Neelin et al. 1998). As subsurface temperature anomalies in the eastern equatorial Pacific are primarily due to thermocline depth anomalies, SST and thermocline depth variability are strongly correlated there. To show the regions in the Atlantic where this type of coupling occurs, SLAs are regressed against SSTAs (Fig. 1c). Since thermocline depth anomalies and SLAs are closely related in the Tropics, this is essentially the same as regressing thermocline depth anomalies against SSTAs. SLAs, however, have a much better spatial coverage. The link between surface and subsurface variations is not due to the expansion of seawater with increase in temperature: a regression value of $0.1 \mathrm{~K} \mathrm{~cm}^{-1}$, typical of the central and eastern Pacific, would be equivalent to a thermal expansion coefficient of $0.002 \mathrm{~K}^{-1}$. Expan- 
sion coefficients for seawater are never greater than $0.00035 \mathrm{~K}^{-1}$. Furthermore, the maximum correlation would be instantaneous and not delayed as observed (see below).

The Atlantic regression pattern (Fig. 1c) is very similar in structure and strength to that of the Pacific (not shown). Regression values in the eastern equatorial Atlantic and south along the west coast of Africa are greater than $0.15^{\circ} \mathrm{C} \mathrm{cm}^{-1}$ and are equal in strength to those found in the corresponding regions of the Pacific. The regression values in the central Atlantic $\left(0.15^{\circ} \mathrm{C}\right.$ $\left.\mathrm{cm}^{-1}\right)$ are somewhat stronger than those in the central Pacific $\left(0.1^{\circ} \mathrm{C} \mathrm{cm}^{-1}\right)$. More significantly though, the explained variance in the Atlantic does not rise much above 0.4 , whereas in the Pacific explained variances in the central Pacific are greater than 0.6 and in the east greater than 0.8 (not shown). The pattern and strength of the correlation between SSTA and SLA in the Atlantic is consistent with analysis of subsurface observations from 1979 to 1999 (Vauclair and du Penhoat 2001), and with ocean model simulations (Carton and Huang 1994; Servain et al. 2000). These results suggest that the third part of the ENSO feedback loop exists in the Atlantic, but that, unlike in the Pacific, other processes also contribute significantly to SST variability in the eastern Atlantic.

The in-phase correlation analysis shows that relationships among zonal winds, SST, and HC in the Atlantic and Pacific are similar, albeit weaker in the Atlantic. To infer a causal relationship among the three fields, and to determine if it is consistent with a closed feedback loop, a cross-correlation analysis was performed for Atlantic and Pacific indices (Fig. 2; Table 1). In the case of a positive feedback (i.e., mutual reinforcement) the cross-correlation function will be more or less symmetric and of the same sign for both positive and negative lags. In the case of a negative or no feedback, the crosscorrelation function will appear antisymmetric or very asymmetric and will peak when the atmosphere leads but drop quickly to zero when the atmosphere lags (Frankignoul and Hasselmann 1977).

For the first element of the Bjerknes feedback, observations indicate that zonal winds in the western Atlantic precede eastern Atlantic SSTA by about 1 month (Fig. 2a; Table 1). This is consistent with previous analysis (Servain et al. 1982; Hirst and Hastenrath 1983). It is also consistent with the relationship in the Pacific, except that in the Pacific the winds lead by about 2 months and the correlation values are weaker in the Atlantic (Fig. 2a; Table 1). The differences in lead time between the Pacific and the Atlantic can be explained by the different zonal scales considered: $60^{\circ}$ and $20^{\circ}$, respectively (i.e., a Kelvin wave must travel (a)

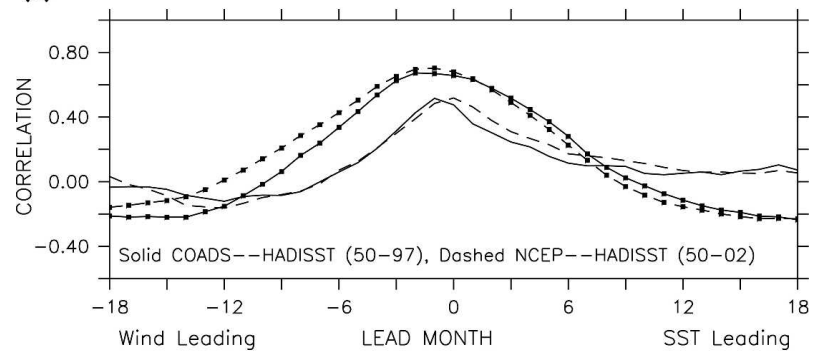

(b)

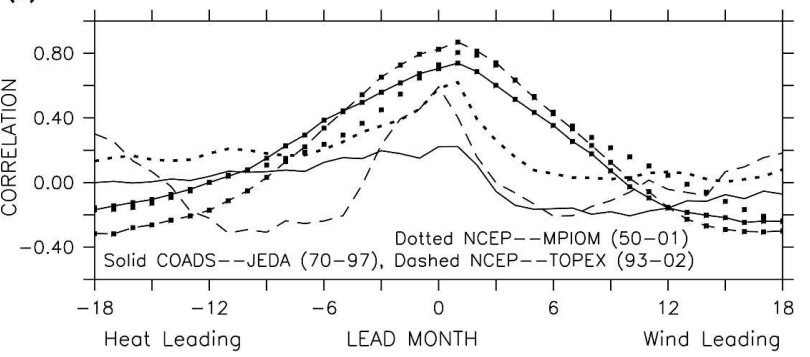

(c)



FIG. 2. The following cross correlations are shown: (a) Atlantic3 SSTA with WAtl 10-m zonal wind speed (1950-97; solid) and with zonal surface stress (1950-2002; dashed), and Niño-3 SSTA with Niño-4 10-m zonal wind speed (1950-97; solid with squares) and with zonal surface stress (1950-2002; dashed with squares); (b) WAtl 10-m zonal wind speed with Atlantic3 400-m heat storage anomalies (HSTs; 1970-2003; solid), WAtl zonal surface stress with Atlantic3 SLA (1993-2002; dashed) and OGCM simulated 400-m average temperature anomalies (1950-2003; solid with squares), and Niño-4 zonal surface stress with Niño-3 SLA (1993-2002; dashed with squares); and (c) Atlantic3 400-m HST and Atlantic3 SSTA (1970-2003; solid), Atlantic3 SLA and Atlantic3 SSTA (1993-2002; dashed), Niño-3 400-m HST and Niño-3 SSTA (1970-2003; solid with squares), and Niño-3 SLA and Niño-3 SSTA (1993-2002; dashed with squares). Data are described fully in section 2 , and $95 \%$ significance levels are given in Table 1.

farther in the Pacific). The influence of other factors in the Atlantic is again indicated by the weaker correlations there. Thus, in both the Pacific and the Atlantic, western-central basin surface zonal wind anomalies force eastern basin SSTAs. It is impossible to determine from a statistical analysis if the eastern basin SSTAs reinforce the wind anomalies, but the shape of 
the cross-correlation functions are consistent with this (Frankignoul and Hasselmann 1977). In the Pacific, it is well accepted that this is the case. In the Atlantic, the in-phase regression pattern of Atlantic3 SST onto winds (Fig. 1a) is highly reminiscent of that in the Pacific, and that expected from theoretical considerations (Gill 1980). In addition, as described above, AGCM studies demonstrate that such a relation also exists in the Atlantic.

For the second element of the Bjerknes feedback, observations indicate that western Atlantic equatorial winds precede $\mathrm{HC}$ variations in the east by around a month, as is consistent with them generating equatorial Kelvin wave variability. However, uncertainty arises as to the strength of the relationship among the observed data: the correlation values estimated from satellite SLA and in situ observations are 0.6 and 0.2 , respectively (Fig. 2b; Table 1). The correlation estimated using SLA data is consistent with that calculated using data from the forced ocean simulation over a longer period (Fig. 2b; Table 1). So it is highly likely that the discrepancy between the observed data arises from the poorer quality of the in situ data, which are derived from sparsely distributed observations (Tourre and White 1995; Servain et al. 2000), and that surface zonal western Atlantic wind variations explain about 35\% of the $\mathrm{HC}$ variability in the eastern Atlantic.

In comparison, central Pacific surface zonal wind variations precede eastern Pacific $\mathrm{HC}$ variations by about 1 month (Fig. 2b; Table 1). The strength of the relationship is consistent among the different datasets. This is perhaps because the in situ data are of better quality in the Pacific and because a larger spatial average is considered in the Pacific. The relationship explains much more variance in the Pacific (approximately $60 \%$ ) than in the Atlantic (Fig. 2b; Table 1). Thus, eastern Atlantic HC is significantly modulated by factors other than western Atlantic wind variability. One factor may be local eastern Atlantic wind variability. In addition to explaining more variance, the relation is also much stronger (3 times in observed data, and 2 times in model data) in the Pacific than in the Atlantic. This is most likely due to the larger spatial extent of coherent wind variations in the Pacific.

Observations indicate that the third elements of the Bjerknes feedback in the Atlantic and Pacific are also similar. In both basins variations in $\mathrm{HC}$ precede SST variations by about a month, consistent with the latter being forced by subsurface variability (Fig. 2c; Table 1). As already discussed above, the explained variance in the Atlantic (50\%) is lower than in the Pacific (80\%), but regression values are about $50 \%$ stronger in the Atlantic, as estimated from SLAs. In contrast, the in



FIG. 3. Standard deviation of Atlantic3 (solid) and Niño-3 (dashed) averaged SSTAs as function of calendar month. SST data are from HadISST for the period 1870-2003.

situ data suggest that the regression values are weaker in the Atlantic, however, as discussed above the quality of the data is significantly poorer. The lower explained variance in the Atlantic would also be consistent with a greater importance of STC or local wind variability in the Atlantic than in the Pacific.

Having estimated the three elements of the Bjerknes feedback it is now possible to estimate the strength of the net feedback in both basins (i.e., a growth rate). In the Atlantic (Pacific), a $1^{\circ} \mathrm{C} \mathrm{SSTA} \mathrm{would} \mathrm{result} \mathrm{in} \mathrm{a} 0.75$ $(0.74) \times 10^{-2} \mathrm{~Pa}$ westerly surface wind stress anomaly, which would in turn, with a 1 month delay, produce a $1.65-\mathrm{cm}(4.7-\mathrm{cm})$ SLA, which would then result in about another month later an SSTA of $0.3^{\circ} \mathrm{C}\left(0.6^{\circ} \mathrm{C}\right)$ (Table 1). Assuming that the delay around the coupled loop is indeed 2 months, then the growth rate in the Pacific is almost twice as strong as in the Atlantic. However, the statistical analysis between wind stress and SST indicates that the delay is about a month less in the Atlantic (Table 1), which would then mean that the growth rates in both basins were similar. Given that the largest difference in this calculation is mainly in the forcing of $\mathrm{HC}$ anomalies by wind stress anomalies, it is most probable that the growth rate is indeed stronger in the Pacific than in the Atlantic, but not twice as strong.

\section{b. Seasonal variations in the Bjerknes feedback}

To this stage our analysis has indicated that the Bjerknes feedback is active in the Atlantic, although it may be weaker and explains less of the variability than in the Pacific. A weaker Bjerknes feedback is consistent with the weaker variability of the Atlantic equatorial mode. In addition to this difference, variability in both basins has quite different seasonality: in the Atlantic variability peaks in boreal summer, and in the Pacific it peaks between November and January (Fig. 3). To explain the different phase locking of variability to the 
(a)

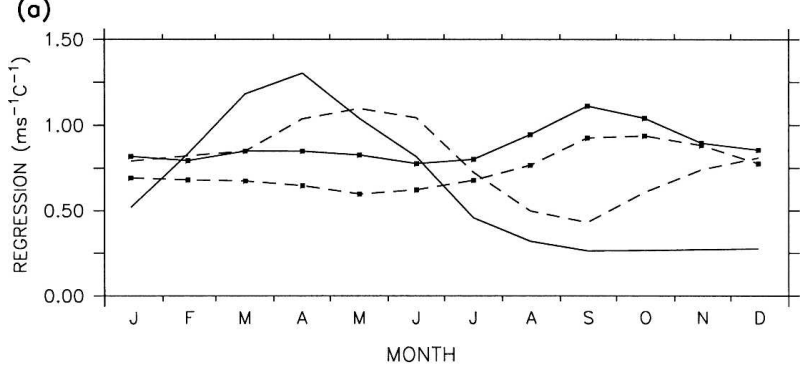

(b)

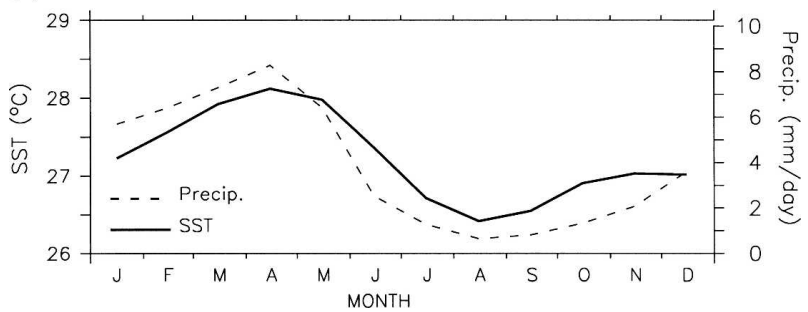

FIG. 4. (a) The following regressions calculated for each calendar month are shown: WAtl 10-m zonal wind speed and Atlantic3 SSTA (1950-1997; solid), WAtl zonal surface stress and Atlantic3 SSTA (1950-2002; dashed; $10^{-2} \mathrm{PaC}^{-1}$ ), Niño-4 10-m zonal wind speed and Niño-3 SSTA (1950-1997; solid with squares), and Niño-4 zonal surface stress and Niño-3 SSTA (1950-2002; dashed with squares). Data were smoothed with a 3-month running mean prior to calculations. (b) Annual cycle (1979-2002) of WAtl SST (solid) and precipitation (dashed).

annual cycle, seasonal variations in the Bjerknes feedback in the Atlantic and Pacific are now described. Seasonal variations in the feedbacks are one possible mechanism for interaction between the seasonal cycle and interannual variability.

The strength of the coupling between eastern Atlantic SST and western Atlantic zonal winds (first element of the Bjerknes feedback) varies significantly over the year, and quite a lot of uncertainty exists among different datasets (Fig. 4a). The strongest regression and correlation (not shown) values occur in May for both NCEP-NCAR reanalysis and COADS wind data. The sensitivity of the atmosphere to SSTAs over the Atlantic is weakest in the boreal autumn. In the COADS data there is in fact almost no sensitivity to SSTAs in boreal autumn. In the Pacific, regression values are of similar strength to those in the Atlantic; correlation values are, however, significantly higher (not shown). In the Pacific, the seasonality in both COADS and NCEP-NCAR reanalysis are in good agreement, with atmosphere sensitivity to SSTA weakest during the period April to July. These features are quite consistent with the seasonality of SST variability in both basins.

Understanding the reasons for this seasonality is non- trivial, since the response of the atmosphere to SSTAs in the Tropics is highly nonlinear, as it involves convection, which depends on both lower-level convergence and absolute SST. The Atlantic differs significantly from the Pacific with respect to tropical convection. In the western tropical Pacific convection is present all year-round, whereas in the western Atlantic it is present from December to May (Fig. 4b) and absent from August through October. This seasonality is determined by the seasonal movements of the intertropical convergence zone (ITCZ), which follow the warmest SST. In the Atlantic the strongest sensitivity seems related to the absolute SSTs in the western Atlantic, which only rise above $28^{\circ} \mathrm{C}$ in May (Fig. 4b). In the western Pacific, where SSTs are always higher than $28^{\circ} \mathrm{C}$, the atmospheric sensitivity seems tied to the eastwest SST contrast (not shown), which is related to the lower-level convergence.

The impact of surface stress anomalies on the ocean is dependent on the vertical oceanic stratification, and thus some seasonality in ocean sensitivity to surface stress anomalies (second element of the Bjerknes feedback) may be expected. This was investigated statistically for both the Pacific and Atlantic basins. The results (not shown), while somewhat inconsistent among the different data, indicate an overall insensitivity to season. This is consistent with equatorial vertical stratification in both these basins being to first order similar throughout the year.

The sensitivity of SST to subsurface variations (third element of the Bjerknes feedback) displays a pronounced seasonality in both the Pacific and Atlantic (Fig. 5a). In the Atlantic, the coupling between surface and subsurface is strongest in the boreal spring to summer seasons. Explained variances in these months are around $0.65(0.5)$ in the satellite-derived SLA (OGCM HC) data. A semiannual component is also evident in the relation, particularly in the satellite data, and is consistent with a secondary maximum in equatorial variability seen in satellite-derived SST (Okumura and Xie 2006). These variations are consistent with SST variability in the Atlantic being strongest in the summer months. In contrast in the Pacific regression values are weakest in the boreal spring, and strong through boreal summer to winter. Explained variances in both datasets are generally greater than 0.65 , except in boreal spring where they reach 0.5 . These seasonal variations are consistent with the variability in the Pacific, and in particular with the spring predictability barrier there.

As already discussed above, the coupling between subsurface-surface in the eastern parts of the basin is primarily determined by the vertical advection of sub- 
(o)

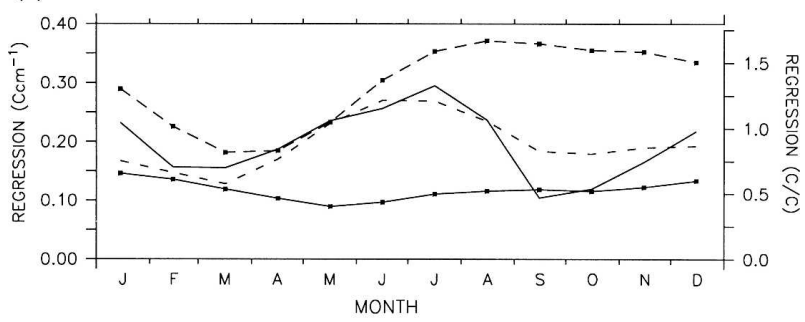

(b)

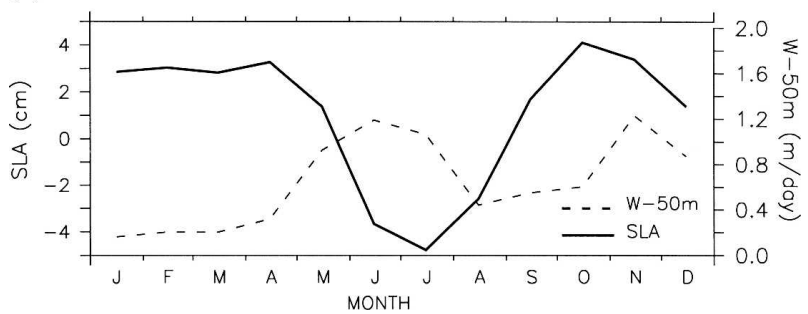

FIG. 5. (a) The following regressions calculated for each calendar month are shown: Atlantic3 SLA and SSTA (1993-2002; solid), Atlantic3 OGCM simulated 400-m average temperature anomalies and SSTA (1950-2001; dashed), Niño-3 SLA and SSTA (1993-2002; solid with squares), and Niño-3 OGCM simulated 400-m average temperature anomalies and SSTA (1950-2001; dashed with squares). Data were smoothed with a 3-month running mean prior to calculations. (b) Annual cycle (1993-2001) of Atlantic3 SLA (solid) and vertical velocity at $50 \mathrm{~m}$ (dashed) from a forced OGCM simulation.

surface temperature anomalies. Thus, seasonal variations in the coupling will result from both variations in mean upwelling and in the mean position of the thermocline depth, since it will control the temperature anomalies at the base of the mixed layer [i.e., perturbations about a deeper (shallow) thermocline will produce weaker (stronger) temperature anomalies at the base of the mixed layer]. The seasonal variations in upwelling and thermocline depth are consistent with the observed variations in subsurface-surface coupling strength (Fig. 5b). The boreal summer peak in subsurface-surface coupling in the Atlantic is the result of both a shallow thermocline and a peak in upwelling. The secondary peak indicated by the satellite data is consistent with a secondary peak in upwelling in November-December [as discussed by Okumura and Xie (2006)]. In the Pacific, the minimum in boreal spring is due to a strong reduction in upwelling, rather than to a deepening of the thermocline (not shown).

In the Atlantic, seasonal variations in SST-surface winds and subsurface-surface coupling mean that the Bjerknes feedback is only active during the boreal spring to summer months. In the Pacific, our analysis indicates that the Bjerknes feedback is active all yearround, although it is weakest in boreal spring. Thus in summary, observations are consistent with coupled interactions similar to those responsible for ENSO being active in the Atlantic. The strength of these interactions appears somewhat weaker in the Atlantic, and more seasonally modulated. This is consistent with Atlantic SST variability being weaker, tied to boreal summer, and less long lasting than in the Pacific.

\section{Discussion and conclusions}

In this paper two questions have been addressed using primarily observational data: Are coupled interactions present in the equatorial Atlantic? And what determines the seasonality of the variability there? Analysis of the three elements of the Bjerknes feedback in both the Atlantic and the Pacific showed that all three elements are present in the equatorial Atlantic and have similar spatial structure and cross-correlation functions as in the Pacific. The combined strength of the feedback in the Atlantic is weaker than that in the Pacific. Furthermore, the variance explained by these interactions is significantly less in the Atlantic than in the Pacific, indicating that other interactions also contribute significantly there. Thus, the answer to the first question is yes, but the net feedback is weaker and hence other mechanisms contribute to SST variability.

The strength of the Bjerknes feedback has a strong seasonal cycle in the Atlantic, and is most affective during boreal spring and summer. The seasonal variations are the result of seasonal variations in the strength of both the atmospheric response to SSTAs, and the SST response to subsurface temperature anomalies. The atmosphere is primarily only sensitive to eastern Atlantic SSTAs during boreal spring and early boreal summer, since it is tied to the seasonal cycle of western Atlantic SSTAs and convection. Eastern Atlantic SSTAs are primarily only affected by subsurface temperature anomalies during late boreal spring and early boreal summer, since during these months the thermocline is shallow enough that subsurface anomalies can affect SST and equatorial upwelling is strongest. Thus the Bjerknes feedback loop in the Atlantic is only closed during boreal spring and summer, meaning that peak equatorial SSTAs occur in boreal summer and disappear thereafter. Seasonal variations in the strength of the Bjerknes feedback in the Pacific are consistent with SSTAs peaking toward the end of the year, but in the Pacific the seasonality is primarily controlled by the seasonal variations in the strength of subsurfacesurface interactions, which are weakest in boreal spring. Thus, the answer to the second question is that the seasonality of the Atlantic equatorial mode is controlled by seasonal variations in the basic state, via modulations of the Bjerknes feedback. The stronger 
seasonal modulation of the Bjerknes feedback in the Atlantic than in the Pacific is consistent with the weaker variability in the Atlantic.

The existence of a delayed negative feedback in the Pacific is as an essential ingredient of ENSO as the positive Bjerknes feedback, and it provides the basis for predictability there. Investigating whether such a feedback also exists in the Atlantic is an important question that was not addressed here. The existence of a delayed negative feedback and its seasonality may also contribute to explaining the strength and seasonality of Atlantic equatorial variability. Its existence would also have important implications for predictability.

Various aspects of the work presented here have already been discussed in the literature. A number of previous observational and modeling studies have investigated the different elements of the coupled feedbacks in the equatorial Atlantic, and their seasonality. The atmospheric sensitivity to eastern Atlantic SSTAs has been shown in observations and in AGCM simulations. The latter have shown that quite a lot of seasonality arises, but in contrast to our results the strongest sensitivity is found in boreal fall. The reasons for this are unclear, but it is somewhat inconsistent with the seasonality of SST variability. The link between SST and subsurface temperature has also been investigated. In previous observational studies, only a weak relationship has been found, but this is most likely due to poor data quality. The modulations of the subsurface surface interaction have also already been linked to thermocline variations but were not clearly demonstrated. Thus, our work is largely consistent with previous studies. However, it extends and consolidates them by investigating all components of the Bjerknes feedback together and comparing their strength and seasonality with the respective feedbacks in the Pacific. The crosscorrelation analysis that further supports the existence of a Bjerknes feedback is a new result.

Our analysis of the coupled feedbacks is entirely consistent with ICM (Zebiak 1993) and HCM studies (Latif and Barnett 1995; Nobre et al. 2003), which indicate that a damped coupled mode exists in the equatorial Atlantic. The conflicting results from CGCMs is also easily understood, since the strength of equatorial coupled variability depends entirely on the ability of the model to simulate the Bjerknes feedback and its seasonality correctly, both of which depend on the climatology of the Atlantic, which is poorly simulated by such models (Davey et al. 2002).

As the equatorial Atlantic mode is likely a damped mode of variability, it is of particular interest to understand how it may be influenced by other modes of vari- (a)



(b)



FIG. 6. (a) Correlation between Niño-3 and Atlantic3 SSTAs for the different calendar months. (b) Cross correlation between Niño-3 and Atlantic3 averaged SSTA. In (a) and (b) solid (dashed) lines are for the period 1970-2003 (1870-2003), and correlations greater than $0.33(0.17)$ are significant at the $95 \%$ level. Values are calculated using monthly mean anomalies from HadISST.

ability. It is well accepted that ENSO has an atmospheric impact over the tropical Atlantic, which includes perturbations to the western Atlantic equatorial zonal surface winds (e.g., Latif and Grötzner 2000). As ENSO exhibits significant predictability, understanding how these zonal wind perturbations may influence the Atlantic is important. Correlation analysis between Niño-3 and Atlantic3 SSTAs shows two interesting features. First, in the last three decades SSTAs in both regions are significantly correlated in boreal spring (Fig. 6a). In early decades essentially no relationship appears to exist. Second, in the last three decades, and to a lesser extent over the last $130 \mathrm{yr}$, Atlantic SSTAs precede anomalies in the Pacific by 6 months (Fig. 6b). The weak relationship that exists when the Pacific variability leads is consistent with the wide disagreement among studies on ENSO's impact on the equatorial Atlantic mode. The interesting observation that Atlantic variability leads Pacific variability has not been discussed, apart from an early work by Wright (1986). Understanding the physical reasons behind the observed statistical Atlantic-Pacific relationship is an important area for future research. The results presented here should provided a basis for interpreting the Pacific-Atlantic interactions. In particular, the strong sea- 
sonality of the ocean-atmosphere feedback in the Atlantic must be taken into account.

Acknowledgments. The significant comments from three anonymous reviewers are greatly acknowledged, so too is the useful criticism from Martin Visbeck and Katja Lohmann. The OGCM simulation was kindly provided by Peter Korn and performed at the Deutsches Klimarechenzentrum. This work was funded by EU projects Dynamite (GOCE 00393) and AMMA (GOCE 004089) and the German BMBF Nordatlantic project (03F0443B).

\section{REFERENCES}

Carton, J. A., and B. Huang, 1994: Warm events in the tropical Atlantic. J. Phys. Oceanogr., 24, 888-903.

Chang, P., L. Ji, and H. Li, 1997: A decadal climate variation in the tropical Atlantic Ocean from thermodynamic air-sea interactions. Nature, $\mathbf{3 8 5}, 516-518$.

— , R. Saravanan, L. Ji, and G. C. Hegerl, 2000: The effect of local sea surface temperatures on atmospheric circulation over the tropical Atlantic sector. J. Climate, 13, 2195-2216.

,$- \ldots$, and — 2003: Tropical Atlantic seasonal predictability: The roles of El Niño remote influence and thermodynamic air-sea feedback. Geophys. Res. Lett., 30, 1501, doi:10.1029/2002GL016119.

Chiang, J. C. H., Y. Kushnir, and A. Giannini, 2002: Deconstructing Atlantic Intertropical Convergence Zone variability: Influence of the local cross-equatorial sea surface temperature gradient and remote forcing from the eastern equatorial $\mathrm{Pa}$ cific. J. Geophys. Res., 107, 4004, doi:10.1029/2000JD000307.

da Silva, A. M., C. C. Young-Molling, and S. Levitus, 1994: Algorithms and Procedures. Vol. 1, Atlas of Surface Marine Data 1994, NOAA Atlas NESDIS 6, 83 pp.

Davey, M., and Coauthors, 2002: STOIC: A study of coupled model climatology and variability in tropical ocean regions. Climate Dyn., 18, 403-420.

Davis, R. E., 1976: Predictability of sea surface temperature and sea level pressure anomalies over the North Pacific Ocean. $J$. Phys. Oceanogr., 6, 249-266.

Dommenget, D., and M. Latif, 2000: Interannual to decadal variability in the tropical Atlantic. J. Climate, 13, 777-792.

Ebisuzaki, W., 1997: A method to estimate the statistical significance of a correlation when the data are serially correlated. $J$. Climate, 10, 2147-2153.

Enfield, D. B., and D. A. Mayer, 1997: Tropical Atlantic sea surface temperature variability and its relation to El NiñoSouthern Oscillation. J. Geophys. Res., 102, 929-945.

Frankignoul, C., and K. Hasselmann, 1977: Stochastic climate models. Part II: Application to SST anomalies and thermocline variability. Tellus, 29, 289-305.

Gill, A., 1980: Some simple solutions for heat induced tropical circulation. Quart. J. Roy. Meteor. Soc., 106, 447-462.

Goddard, L., and S. J. Mason, 2002: Sensitivity of seasonal climate forecasts to persisted SST anomalies. Climate Dyn., 19, 619631.

Hirst, A. C., and S. Hastenrath, 1983: Atmosphere-ocean mechanisms of climate anomalies in the Angola-tropical Atlantic sector. J. Phys. Oceanogr., 13, 1146-1157.

Houghton, R. W., and C. Colin, 1986: Thermal structure along $4^{\circ} \mathrm{W}$ in the Gulf of Guinea during 1983-4. J. Geophys. Res., 91, $11727-11740$.

Huang, B., P. S. Schopf, and J. Shukla, 2004: Intrinsic oceanatmosphere variability of the tropical Atlantic ocean. J. Climate, 17, 2058-2077.

Illig, S., B. Dewitte, N. Ayoub, Y. du Penhoat, G. Reverdin, P. D Mey, F. Bonjean, and G. S. E. Lagerloef, 2004: Interannual long equatorial waves in the tropical Atlantic from a highresolution ocean general circulation model experiment in 1981-2000. J. Geophys. Res., 109, C02022, doi:10.1029/ 2003JC001771.

Kalnay, E., and Coauthors, 1996: The NCEP/NCAR 40-Year Reanalysis Project. Bull. Amer. Meteor. Soc., 77, 437-471.

Latif, M., and T. P. Barnett, 1995: Interactions of the tropical oceans. J. Climate, 8, 952-964.

— , and A. Grötzner, 2000: The equatorial Atlantic oscillation and its response to ENSO. Climate Dyn., 16, 213-218.

Levitus, S., R. Burgett, and T. P. Boyer, 1994: Salinity. Vol. 3 , World Ocean Atlas 1994, NOAA Atlas NESDIS 3, 99 pp.

Marsland, S., H. Haak, J. Jungclaus, and M. Latif, 2003: The MaxPlanck-Institute global ocean/sea ice model with orthogonal curvilinear coordinates. Ocean Modell., 5, 91-127.

Merle, J., M. Fieux, and P. Hisard, 1980: Annual signal and interannual anomalies of sea surface temperature in the eastern equatorial Atlantic ocean. Deep-Sea Res., 26, 77-101.

Neelin, J. D., D. S. Battisti, A. C. Hirst, F.-F. Jin, Y. Wakata, T. Yamagata, and S. E. Zebiak, 1998: ENSO theory. J. Geophys. Res., 103, 14 261-14 290.

Nobre, P., S. E. Zebiak, and B. P. Kirtman, 2003: Local and remote sources of tropical Atlantic variability inferred from the results of a hybrid ocean-atmosphere coupled model. Geophys. Res. Lett., 30, 8008, doi:10.1029/2002GL015785.

Okumura, Y., and S.-P. Xie, 2006: Some overlooked features of tropical Atlantic climate leading to a new Niño-like phenomenon. J. Climate, 19, 5859-5874.

Penland, C. M., and L. Matrosova, 1998: Prediction of tropical Atlantic sea surface temperatures using linear inverse modeling. J. Climate, 11, 483-496.

Philander, S. G. H., 1986: Unusual conditions in the tropical Atlantic Ocean in 1984. Nature, 322, 236-238.

Rayner, N. A., D. E. Parker, E. B. Horton, C. K. Folland, L. V. Alexander, D. P. Rowell, R. E. C. Kent, and A. Kaplan, 2003: Global analyses of sea surface temperature, sea ice, and night marine air temperature since the late nineteenth century. $J$. Geophys. Res., 108, 4407, doi:10.1029/2002JD002670.

Ruiz-Barradas, A., J. A. Carton, and S. Nigam, 2000: Structure of interannual-to-decadal climate variability in the tropical Atlantic sector. J. Climate, 13, 3285-3297.

Saravanan, R., and P. Chang, 2000: Interaction between tropical Atlantic variability and El Niño-Southern Oscillation. J. Climate, 13, 2177-2194.

Servain, J., J. Picaut, and J. Merle, 1982: Evidence of remote forcing in the equatorial Atlantic Ocean. J. Phys. Oceanogr., 12, 457-463.

- I. Wainer, J. P. McCreary, and A. Dessier, 1999: Relationship between the equatorial and meridional modes of climate variability in the tropical Atlantic. Geophys. Res. Lett., 26, 458-488.

, — , H. L. Ayina, and H. Roquet, 2000: The relationship between the simulated climate variability modes of the tropical Atlantic. Int. J. Climatol., 20, 939-953. 
Sutton, R. T., S. P. Jewson, and D. P. Rowell, 2000: The elements of climate variability in the tropical Atlantic region. J. Climate, 13, 3261-3284.

Tourre, Y. M., and W. B. White, 1995: ENSO signals in global upper-ocean temperature. J. Phys. Oceanogr., 25, 1317-1332.

Vauclair, F., and Y. du Penhoat, 2001: Interannual variability of the upper layer of the tropical Atlantic from in situ data between 1979 and 1999. Climate Dyn., 17, 527-546.

Wagner, R. G., and A. M. da Silva, 1994: Surface conditions associated with anomalous rainfall in the Guinea coastal region. Int. J. Climatol., 14, 179-199.
Wright, P. B., 1986: Precursors of the Southern Oscillation. J. Climatol., 6, 17-30.

Wu, L., Q. Zhang, and Z. Lui, 2002: Search for the role of ENSO in tropical Atlantic variability using a coupled GCM. CLIVAR Exchanges, Vol. 7, International CLIVAR Project Office, Southampton, United Kingdom, 20-24.

Xie, P., and P. A. Arkin, 1997: Global precipitation: A 17-year monthly analysis based on gauge observations, satellite estimates, and numerical model outputs. Bull. Amer. Meteor. Soc., 78, 2539-2558.

Zebiak, S. E., 1993: Air-sea interaction in the equatorial Atlantic region. J. Climate, 6, 1567-1586. 